\title{
LAYOUT DE TECLADO PARA UMA PRANCHA DE COMUNICAÇÃO ALTERNATIVA E AMPLIADA ${ }^{1}$ \\ Keyboard Layout For an augmentative and alternative COM MUNiCATION \\ BOARD
}

\author{
Luciane A parecida LIEGEL ${ }^{2}$ \\ Milena Maria Rodege GOGOLA ${ }^{3}$ \\ Percy NOHAMA ${ }^{4}$
}

RESU M 0: o objetivo deste artigo é descrever e discutir a proposta de um novo layout de teclado projetado especialmente para uma prancha de comunicação alternativa com acionamento mecânico e remoto, para ser utilizado por portadores de paralisia cerebral com capacidade cognitiva preservada. Para compor o layout do teclado de comunicação alternativa, realizou-se uma pesquisa envolvendo disposição e conteúdo das teclas. Participaram do estudo onze voluntárias, sendo: cinco professoras de educação especial, quatro pedagogas especializadas em educação especial e duas fonoaudiólogas. O layout é composto por 95 teclas dispostas em grupos de teclas: alfabéticas, de letras acentuadas, numéricas, de funções e de comunicação alternativa e ampliada. As teclas de comunicação alternativa, contêm ícones associados à palavras ou frases, além de teclas acentuadas. Os ícones contemplados fazem parte de uma linguagem visual brasileira de comunicação, em desenvolvimento. Para auxiliar na localização, tanto o tamanho de teclas e caracteres quanto as cores de fundo das teclas diferenciadas foram utilizadas. As teclas com letras acentuadas e as teclas de comunicação alternativa visam facilitar e acelerar a digitação das mensagens, reduzindo assim o tempo de digitação e conseqüentemente, a ocorrência de fadiga muscular.

PALA VRAS-CHAVE: comunicação alternativa; layout de teclado; interface homem-máquina; prancha de comunicação; educação especial.

\begin{abstract}
: the aim of this article is to describe and discuss a novel layout proposal for keyboard especially designed for a communication board using mechanical and remote activation to be used by people with cerebral paralysis who present sufficient cognitive skills. In order to design the layout of the augmentative and alternative communication keyboard, a research study involving position and content of the keys was undertaken. Eleven volunteers participated in the study, and they were: five special education teachers, four pedagogues specialized in special education and two speech and language therapists. The layout is made up of 95 keys positioned into key-groups: alphabetical, number, keyboard functions, accented letters and alternative communication. The alternative communication keys contain signs associated with words or phrases, besides keys with accents. These signs are part of a Brazilian visual communication language that is under development. In order to facilitate key finding, both size and background color were considered. The purpose of the accented letters and alternative communication keys is to facilitate key finding and enhance typing speed so as to reduce muscular fatigue.
\end{abstract}

KEYWORDS: augmentative and alternative communication; keyboard layout; man/ machine interface; communication board; special education.

\footnotetext{
${ }^{1}$ Os autores agradecem à FINEP pelo apoio financeiro e pelas bolsas, e à Escola de Educação Especial Vivian Marçal pelo estímulo e inestimável colaboração

2 Discente do Curso de de Pós-Graduação em Tecnologia em Saúde da Pontifícia Universidade Católica do Paraná - Iucianeliegel@ufpr.BR

${ }^{3}$ Professora do curso de Design da UTFPR e UTP. - milenamrg@gmail.com

${ }^{4}$ Professor do Programa de Pós-Graduação em Tecnologia em Saúde da Pontifícia Universidade Católica do Paraná - percy.nohama@gmail.com
} 


\section{INTRODUÇão}

A comunicação é uma necessidade básica do ser humano (LEDESMA; DEL TORO, 2004). Ela envolve um vasto entrelaçamento de informações, que podem ser manifestadas por meio deelementos motores, de expressão emocional, vocal izações, podendo ind usiveocorrer sem linguagem (BOONE; PLANTE, 1994).

Pessoas com necessidades especiais que não possuem ou perderam a capacidade de comunicação convencional, necessitam de auxílio para se comunicarem. Esse auxílio pode vir da tecnologia assistiva (KING, 1999), em especial da área denominada de comunicação al ternativa e aumentativa (PELOSI, 2005).

A comunicação alternativa e aumentativa define toda forma de comunicação além da convencional, como o uso de sinais manuais, expressões faciais, pranchas de comunicação incluindo símbolos gráficos e sistemas de computação (PELOSI, 2005).

No Brasil existem cerca de 24,5 milhões de pessoas com deficiência, totalizando 14,5\% da população; desses cerca de 30.000 a 40.000 são crianças diagnosticadas como portadoras de paralisia cerebral (SICORDE, 2008).

Um estudo realizado com 100 crianças com paralisia cerebral, aplicando o teste de inteligência de Binet, mostrou que em $45 \%$ dessas crianças, o QI (quociente de inteligência) estava abaixo de 70 e $28 \%$ delas, encontrava-se acima de 90 . Esses dados foram comparados com o QI médio de crianças hígidas que é de 68 (VA LENTE, 2008). Portanto, crianças portadoras de paralisia cerebral podem ser beneficiadas com o desenvolvimento denovas ferramentas que auxiliem na comunicação.

A tualmente, com o rápido e constante desenvolvimento da informática, o computador passou a ser utilizado como ferramenta para auxiliar pessoas com deficiências físicas emotoras. Entretanto, técnicas especiais de acesso ao computador devem ser utilizadas. Para tanto, hardwares e softwares são adaptados para atender às necessidades especiais desses usuários.

Os principais componentes de hardware de computador adaptados para comunicação alternativa, constituem-se aos teclados e mouses e joysticks. Os teclados geralmente utilizam teclas ampliadas e acessórios de acionamento (WEBSTER et al., 1985; SHIRMER; BROWNING; BERSCH, 2007). Além do acionamento mecânico, existem teclados ativados remotamente via laser (CHEN et al., 1999). Os mouses são projetados com botões que permitem o movimento do cursor do mouse para cima, para baixo, para os lados, além das funções arrastar e selecionar (CLIK, 2008). Os mouses também podem ter acionamento remoto como, por exemplo, o acionamento via sinal infravermelho ou movimento da cabeça usando câmera de vídeo (JORDAN et al., 2004; OSOWSKY et al., 2004a,b). 
Entretanto, alguns destes dispositivos apresentam elevado custo, limitações de uso e exigem potencial cognitivo para instalação e manuseio (JORDAN et al., 2004).

Diante do exposto, visando contribuir com uma nova ferramenta de comunicação alternativa para ser utilizada por portadores de paralisia cerebral com capacidade cognitiva preservada e coordenação motora para acionar teclas; neste artigo, discute-se a opinião e possíveis mudanças sobre um novo layout de teclado para compor um sistema computadorizado. O layout apresenta teclas com características de um teclado convencional e teclas especiais de comunicação contendo ícones da Linguagem Visual Brasileira. ${ }^{5} \mathrm{O}$ sistema informatizado encontra-se em fase de testes, pode ser acionado de forma mecânica e remota via sinal infravermelho; portanto, a disposição e o tamanho das teclas seguem as necessidades dos usuários e as adaptações ao hardware do sistema.

\section{Material e método}

Fizeram parte do presente estudo onze voluntárias, sendo: cinco professoras de educação especial, quatro pedagogas especialistas em educação especial e duas fonoaudiólogas. Todas as voluntárias trabal ham em escola de educação especial que atende pessoas com deficiência motora e deficiências múltiplas, secundárias às patologias neurológicas, em faixa etária de zero a trinta e cinco anos.

A coleta de dados foi realizada na sala de informática da escola de educação especial e teve duração de três dias.

Cada voluntária recebeu aleatoriamente um número de identificação de 1 a 11 , analisou as propostas de layout de teclado e teve um tempo de 30min para responder a um questionário sobre o layout de teclado para comunicação alternativa. Todas as voluntárias preencheram individualmente o Termo de Consentimento Livre e Esclarecido (Parecer $n^{\circ} 1408$ de 25/ 11/ 2006, Comitê de Ética em Pesquisa da PUCPR).

Para o desenvolvimento de um layout de teclado para prancha de comunicação alternativa, partiu-se de estudos semelhantes feitos anteriormente com a Proposta de Layout de Teclado para Comunicação Alternativa (LIEGEL; NOHAMA, 2005). O layout inicial, representado na Figura 1, apresentava teclas de comunicação alternativa, alfabéticas, letras acentuadas e teclas de funções. A distribuição dos grupos de teclas era baseada no padrão do teclado convencional; assim como o tamanho das teclas alfabéticas, letras acentuadas e numéricas. As

\footnotetext{
${ }^{5}$ Linguagem baseada em figuras, proposta pelo grupo de pesquisa do Dr. Nohama, no projeto “Sistema Portátil de Comunicação Alternativa", financiado pela FINEP (ref. 2198/ 05), envolvendo a UTFPR e a PUCPR.
} 
teclas de comunicação alternativa estavam dispostas na parte superior do teclado e continham ícones no canto inferior esquerdo das teclas e legenda na parte superior da teclas.

O layout foi estudado e baseando-se no princípio de que a Tecnologia Assistiva possui características multidisciplinares, a metodologia de design foi aplicada para desenvolver uma proposta adequada para a interface do teclado.

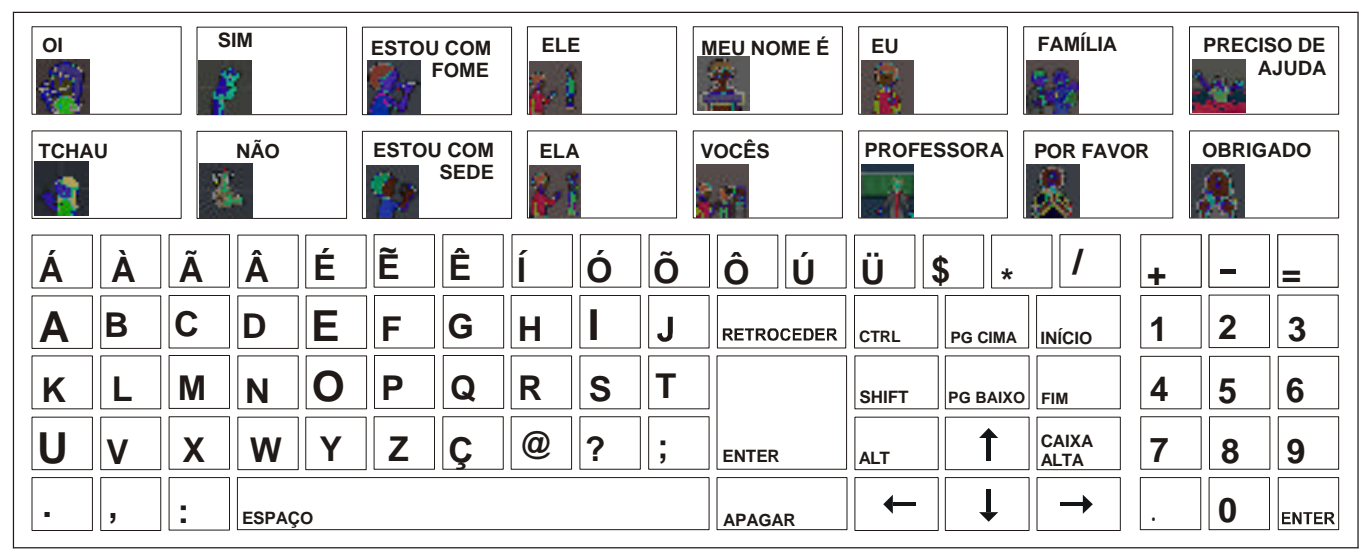

Figura 1 - Layout inicial do teclado para comunicação alternativa.

Segundo a definição de Itiro lida, "legível" é a forma das letras que corresponde ao "modelo interno", que é aprendido na fase de alfabetização dos indivíduos, cuja leitura das letras é feita individualmente. $\mathrm{O}$ conceito de legibilidade considera que a uma distância de $45 \mathrm{~cm}$, os caracteres devem ser reconhecidos e lidos rapidamente e sem esforço, e que depende do espaçamento entre eles, das combinações entre caracteres e das margens envolvidas na diagramação do material gráfico (RICHAUDEAU; MENDIBELZÚA, 1979).

Baseando-se nesse conceito, adotou-se, para compor a primeira proposta de layout do teclado, apresentado na Figura 2, o uso de teclas básicas de 2,5cm x 2,5cm e de comunicação alternativa contendo ícones de 3,5cm x 3,5cm e teclas de funções de $5,0 \mathrm{~cm} \times 2,5 \mathrm{~cm}$ ou de $5,0 \mathrm{~cm} \times 5,0 \mathrm{~cm}$. Os caracteres, utilizando fonte A rial, seguiram um padrão de: $3 \mathrm{~mm}$ para compor as teclas com legendas; $8,5 \mathrm{~mm}$ para compor as consoantes e $10 \mathrm{~mm}$ para compor as vogais.

Algumas características presentes no layout inicial foram aproveitadas para compor o novo layout. O bloco das teclas especiais de comunicação foi disposto na parte superior do teclado, os ícones pertencentes à Linguagem Brasileira de Comunicação Pictográfica foram escolhidos a partir dos dados obtidos em pesquisa anterior (LIEGEL; NOHAMA, 2005). Para facilitar a visualização, digitação em termos de tempo de digitação e fadiga muscular (JORDAN; HATTORI; 
NOHAMA, 2004), o uso das teclas acentuadas foi mantido; porém, foram separadas do bloco das teclas alfabéticas. As teclas numéricas foram dispostas em seqüência numérica na parte superior das teclas acentuadas e os tamanhos das teclas "RETROCEDER", “ENTER" e "ESPAÇO” foram mantidos.

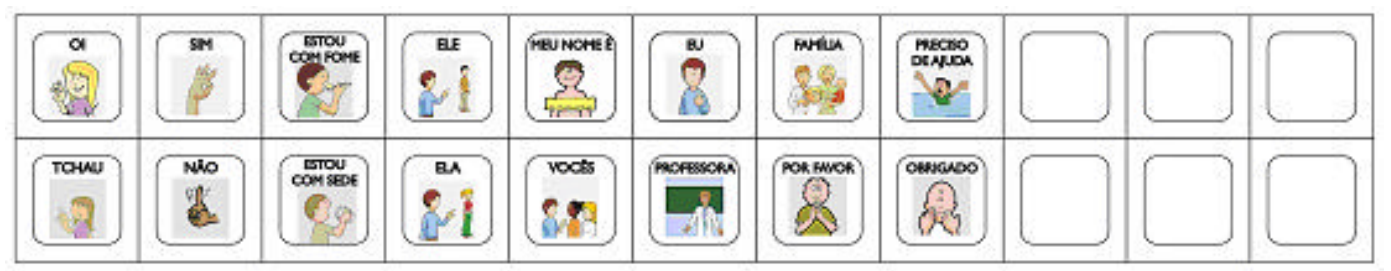

\begin{tabular}{|c|c|c|c|c|c|c|c|c|c|c|c|c|c|}
\hline 1 & 2 & 3 & 4 & 5 & 6 & 7 & 8 & 9 & 0 & + & - & $*$ & $I$ \\
\hline $\bar{A}$ & $\AA$ & $\hat{\mathbf{A}}$ & $\tilde{\mathbf{A}}$ & É & $\hat{\mathbf{E}}$ & $\widetilde{\mathbf{E}}$ & 1 & 0 & $\hat{0}$ & $\tilde{0}$ & Ú & Uे & $\ddot{U}$ \\
\hline
\end{tabular}

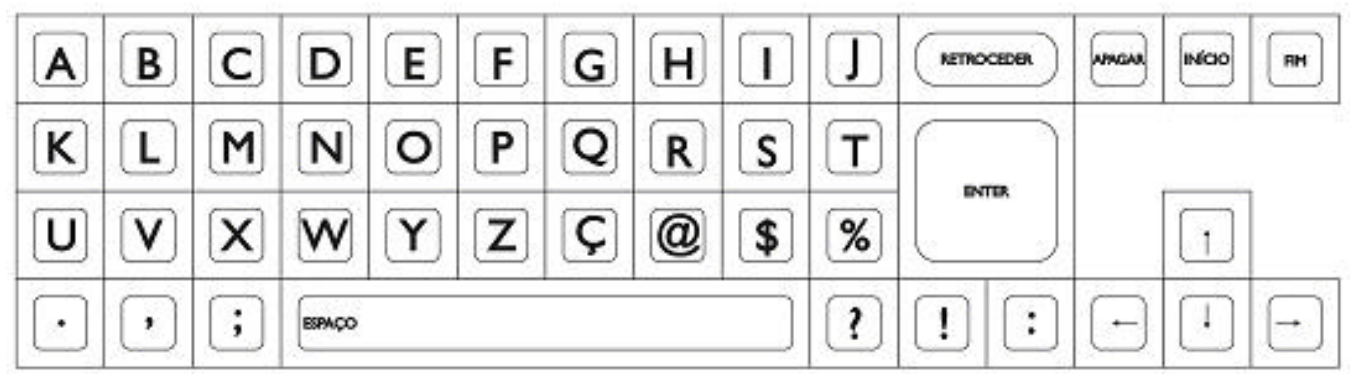

Figura 2 - Primeira proposta de layout de teclado para comunicação alternativa.

Como o layout será utilizado em um sistema informatizado de comunicação alternativa, o mesmo deve ser adaptado ao hardware do sistema. Para tanto, todas teclas possuem contornos para limitar os caracteres e ícones em um espaço suficiente para visualização, sobrando um espaço para o posicionamento de 1 receptor de infravermelho de $3 \mathrm{~mm}$, localizado no canto superior direito de cada e de 1 LED de sinalização de $3 \mathrm{~mm}$ de acionamento de tecla, localizado no canto superior esquerdo de cada tecla.

Considerando-se os princípios da Tecnologia Assistiva e para que as modificações e os desafios funcionais fossem superados pela intervenção de outras soluções (SCHIRM ER, 2004), uma nova distribuição e dimensionamento de teclas foram aplicados no projeto.

O tamanho e o posicionamento das teclas especiais de comunicação e das teclas alfabéticas foi mantido; porém, diminuíram-se as dimensões de algumas teclas de funções. Além disso, foram incluídas al gumas teclas especiais, 
e as teclas "TAB", "CapsLock" e "CTRL". No lugar das teclas "A pagar", "Início" e "Fim" foram inseridas as teclas de funções "Iniciar", "A brir", "Fechar" e "Salvar", e foi aplicada a cor cinza no contorno destas, além da cor verde no contorno do "ENTER" e da cor vermelha no contorno do "BACKSPACE", conforme a segunda proposta de layout apresentada na Figura 3.

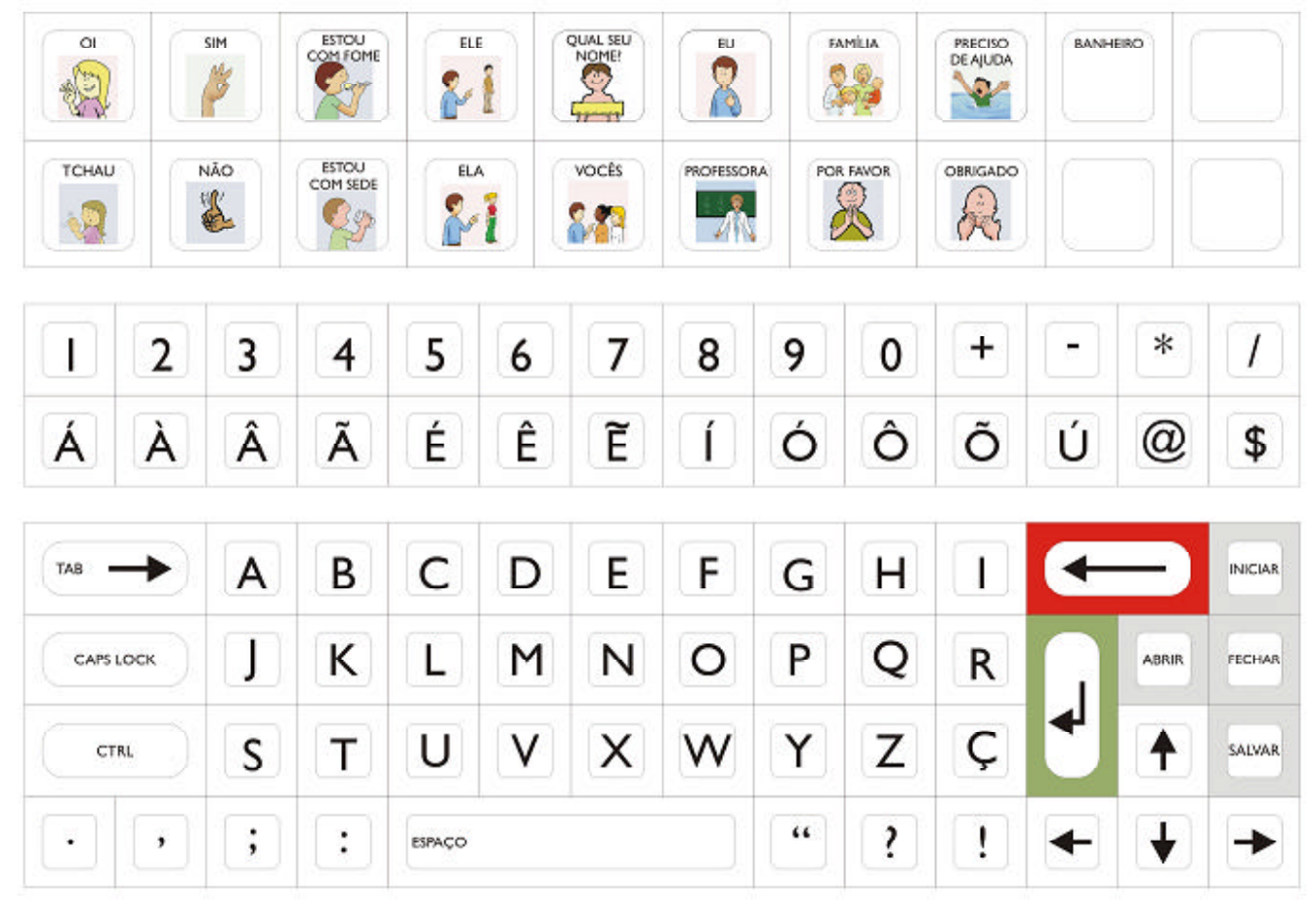

Figura 3 - Segunda proposta de layout de teclado para comunicação alternativa.

Para otimizar a sua distribuição e visual ização das teclas no teclado, uma nova análise do layout foi realizada, o que levou a concepção de um layout novo, apresentado na Figura 4. Observa-se que as teclas "TAB", "CAPS LOCK", "CTRL", receberam contorno cinza, a tecla "ENTER" foi ampliada e recebeu contorno azul. N otam-se modificações na disposição e conteúdo das teclas, pois as teclas "INICIAR", "ABRIR", "FECHAR" e "SALVAR" foram substituídas pelas teclas "INS', 'DEL", "CLICAR" e "CLICAR 2X", com o intuito de permitir o uso do mouse acionado diretamente no teclado. Esse layout teste do teclado foi apresentado às voluntárias. 
O layout teste era composto por 96 teclas divididas em 5 grupos de teclas: alfabéticas, numéricas, de funções, letras acentuadas e especiais de comunicação. A pós o grupo de teclas especiais de comunicação, estava disposto o grupo das teclas acentuadas em conjunto com grupo das teclas numéricas, formando apenas um bloco. Para finalizar, o último bloco continha os grupos de teclas alfabéticas e de funções.

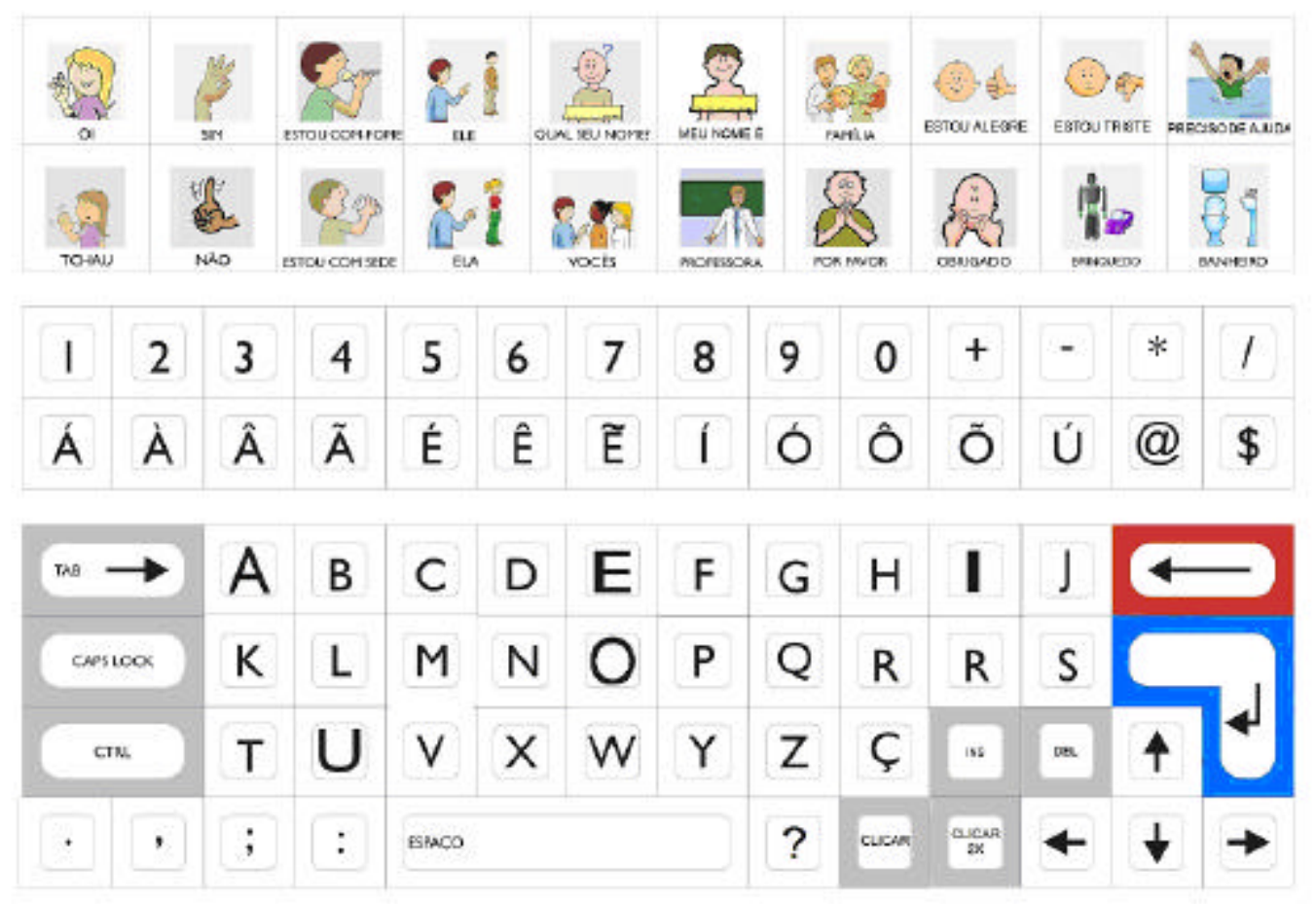

Figura 4 - Layout teste de teclado para comunicação al ternativa.

Por se tratar de um layout para prancha de comunicação, a seqüência numérica e alfabética das teclas foi adaptada a partir da pesquisa da terapeuta Myriam Pelosi (PELOSI, 2005). Entretanto, a disposição da seqüência alfabética pode ser al terada para a seqüência ABNT presente no teclado convencional, para usuários que já possuem experiência de utilização de tal seqüência.

Uma explicação geral a respeito da pesquisa foi apresentada às voluntárias. Essa explicação, para não interferir na opinião individual de cada voluntária, limitou-se à apresentação do nome dos grupos de teclas: alfabéticas, numéricas, de funções, letras acentuadas e especiais de comunicação; além de uma sucinta explicação sobre o conteúdo desses grupos. 
O questionário, apresentado às voluntárias, era composto por 23 perguntas. Destas, 21 receberam individualmente uma nota com valor variável de 0 a 10 e referiam-se à facilidade de localização e visualização das tedas e dos grupos de teclas, cores e tamanhos e cores apropriados, caracteres e ícones e facilidade de compreensão do layout. Essas 21 perguntas, encontram-se no Quadro 1.

N as 2 últimas questões, solicitou-se das voluntárias sugestões defrases ou palavras do cotidiano de portadores de paralisia cerebral com capacidade cognitiva preservada e possíveis modificações no layout do teclado.

\begin{tabular}{l|lllllllllll}
\hline \multicolumn{1}{c|}{ Questões } & \multicolumn{1}{c}{ Nota } \\
\hline Os grupos de teclas são de fácil localização? & 0 & 1 & 2 & 3 & 4 & 5 & 6 & 7 & 8 & 9 & 10 \\
A separação por grupos de teclas facilita a localização das teclas? & 0 & 1 & 2 & 3 & 4 & 5 & 6 & 7 & 8 & 9 & 10 \\
O tamanho do teclado é apropriado? & 0 & 1 & 2 & 3 & 4 & 5 & 6 & 7 & 8 & 9 & 10 \\
O tamanho das teclas alfabéticas é apropriado? & 0 & 1 & 2 & 3 & 4 & 5 & 6 & 7 & 8 & 9 & 10 \\
O tamanho das teclas numéricas é apropriado? & 0 & 1 & 2 & 3 & 4 & 5 & 6 & 7 & 8 & 9 & 10 \\
O tamanho das teclas de funções é apropriado? & 0 & 1 & 2 & 3 & 4 & 5 & 6 & 7 & 8 & 9 & 10 \\
O tamanho das teclas especiais de comunicação é apropriado? & 0 & 1 & 2 & 3 & 4 & 5 & 6 & 7 & 8 & 9 & 10 \\
O tamanho dos caracteres das teclas alfabéticas é apropriado? & 0 & 1 & 2 & 3 & 4 & 5 & 6 & 7 & 8 & 9 & 10 \\
O tamanho dos caracteres das teclas numéricas é apropriado? & 0 & 1 & 2 & 3 & 4 & 5 & 6 & 7 & 8 & 9 & 10 \\
O tamanho dos caracteres das teclas de funções é apropriado? & 0 & 1 & 2 & 3 & 4 & 5 & 6 & 7 & 8 & 9 & 10 \\
O tamanho dos caracteres das teclas especiais é apropriado? & 0 & 1 & 2 & 3 & 4 & 5 & 6 & 7 & 8 & 9 & 10 \\
As teclas alfabéticas podem ser bem visualizadas? & 0 & 1 & 2 & 3 & 4 & 5 & 6 & 7 & 8 & 9 & 10 \\
As teclas numéricas podem ser bem visualizadas? & 0 & 1 & 2 & 3 & 4 & 5 & 6 & 7 & 8 & 9 & 10 \\
As teclas de funções podem ser bem visualizadas? & 0 & 1 & 2 & 3 & 4 & 5 & 6 & 7 & 8 & 9 & 10 \\
As teclas especiais de comunicação podem ser bem visualizadas? & 0 & 1 & 2 & 3 & 4 & 5 & 6 & 7 & 8 & 9 & 10 \\
A cor preta usada para os caracteres é apropriada? & 0 & 1 & 2 & 3 & 4 & 5 & 6 & 7 & 8 & 9 & 10 \\
A cor branca usada como fundo para os caracteres é apropriada? & 0 & 1 & 2 & 3 & 4 & 5 & 6 & 7 & 8 & 9 & 10 \\
O uso de cores diferentes facilita a localização das teclas? & 0 & 1 & 2 & 3 & 4 & 5 & 6 & 7 & 8 & 9 & 10 \\
O uso de letras ampliadas facilita a localização das vogais? & 0 & 1 & 2 & 3 & 4 & 5 & 6 & 7 & 8 & 9 & 10 \\
O layout de tecladón de fácil compreensão? & 0 & 1 & 2 & 3 & 4 & 5 & 6 & 7 & 8 & 9 & 10 \\
\hline
\end{tabular}

Quadro 1 - Questões do questionário apresentado às voluntárias.

\section{RESUltados}

Para compor os gráficos apresentados a seguir, a média das notas para cada pergunta foi calculada para cada voluntária. Em seguida, esses dados foram transformados em percentual. As perguntas foram agrupadas nos seguintes temas: facilidade de localização, tamanho adequado, tamanho de caracteres, facilidade de visualização, cores, letras ampliadas e layout de teclado.

Na Figura 5, ilustra-se o gráfico da média de aprovação das características do lay out teste, presentes nas 21 perguntas apresentadas no Quadro 1 vs. voluntárias. Podese observar que as características foram aprovadas em: $100 \%$ pelas voluntárias 4, 5, 6, 7,e 8; 99,52\% pela voluntária 3; 99,04\% pelas voluntárias 1 e 11; 97,14\% pela a voluntária 2 e 94, 76\% pelas voluntárias 9 e 10. 


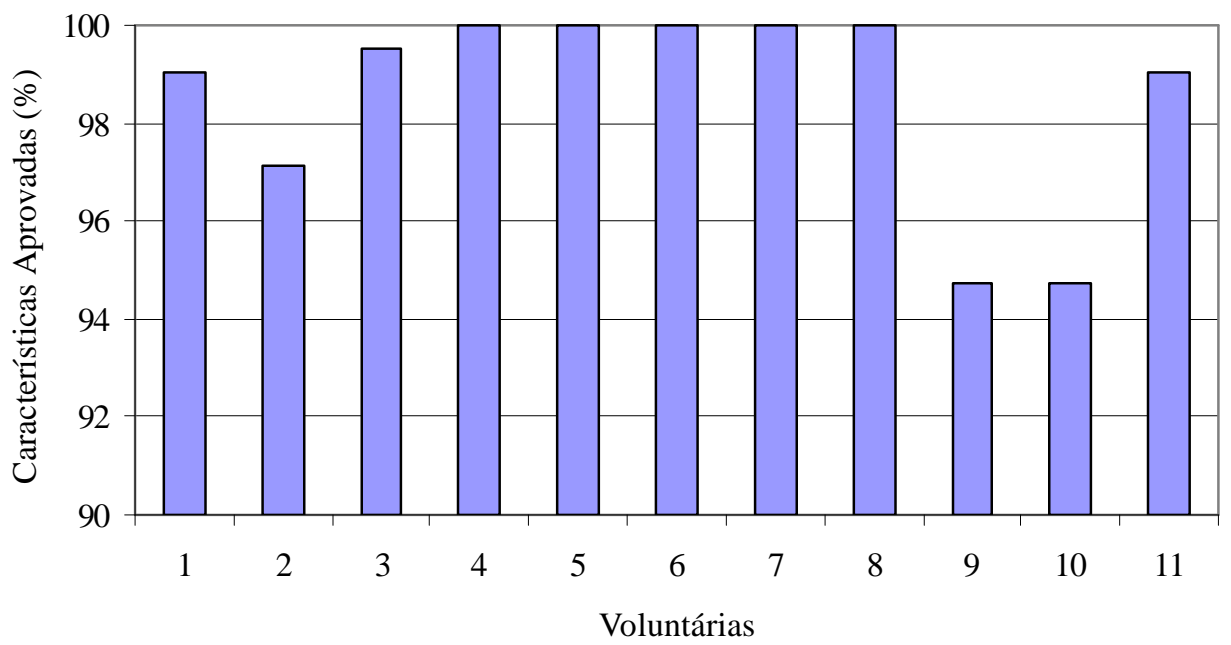

Figura 5 - Representação da média de aprovação das características presentes nas 21 perguntas do Quadrol vs. voluntárias.

Os resultados relativos à aprovação quanto à facilidade de localização de grupos de teclas e localização das teclas devido à separação em grupos, podem ser observados na Figura 6.

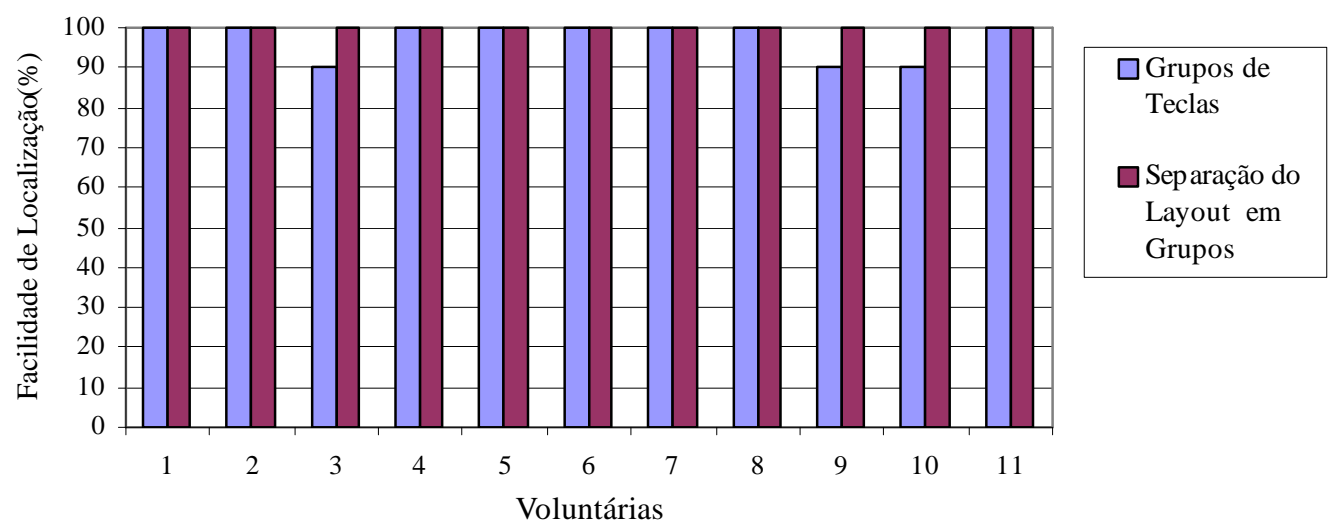

Figura 6 - Representação da taxa de aprovação (em percentual) da facilidade de localização dos grupos de teclas e separação das teclas em grupos vs. voluntárias. 
$\mathrm{Na}$ Figura 7, pode-se observar a representação em porcentagem do tamanho adequado do teclado, teclas alfabéticas, teclas numéricas, teclas de funções e teclas especiais de comunicação vs. voluntárias.

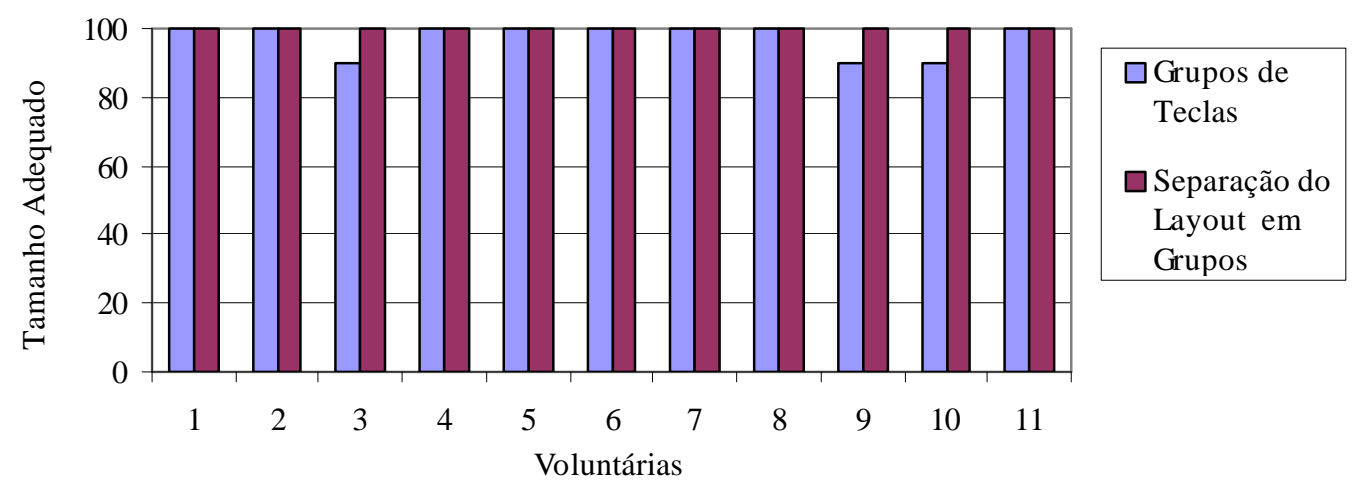

Figura 7 - Representação do tamanho adequado do teclado, teclas alfabéticas, teclas numéricas, teclas de funções e teclas especiais de comunicação vs. voluntárias.

Os resultados referentes ao índice de aceitação dos tamanhos dos caracteres das teclas alfabéticas, numéricas, de funções, especiais de comunicação, encontram-se ilustrados na Figura 8.

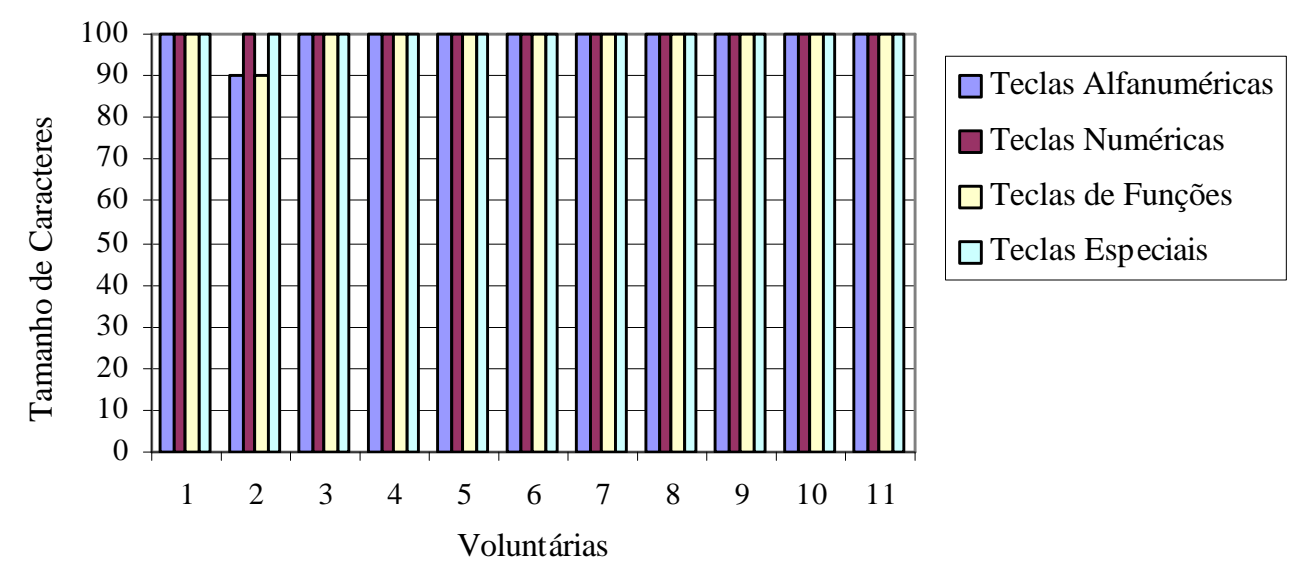

Figura 8 - Representação da aceitação do tamanho de caracteres das teclas alfabéticas, teclas numéricas, teclas de funções e teclas especiais de comunicação vs. voluntárias. 
A Figura 9 abrange os resultados das questões referentes à facilidade de visualização das teclas e ícones vs. voluntárias.

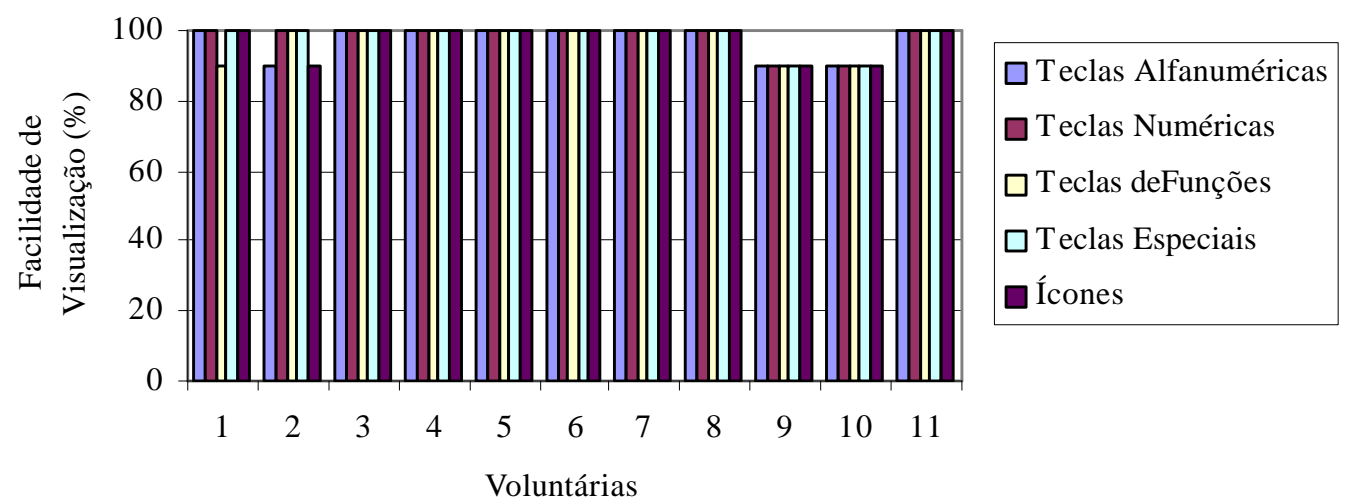

Figura 9 - Representação dos resultados relativos à facilidade de visual ização das teclas: alfabéticas, numéricas, de funções, especiais de comunicação e ícones vs. voluntárias.

A Figura 10 ilustra os resultados da avaliação do emprego das cores para facilitar a localização das teclas: preta para compor os caracteres, branca e diferenciadas como fundo dos caracteres.

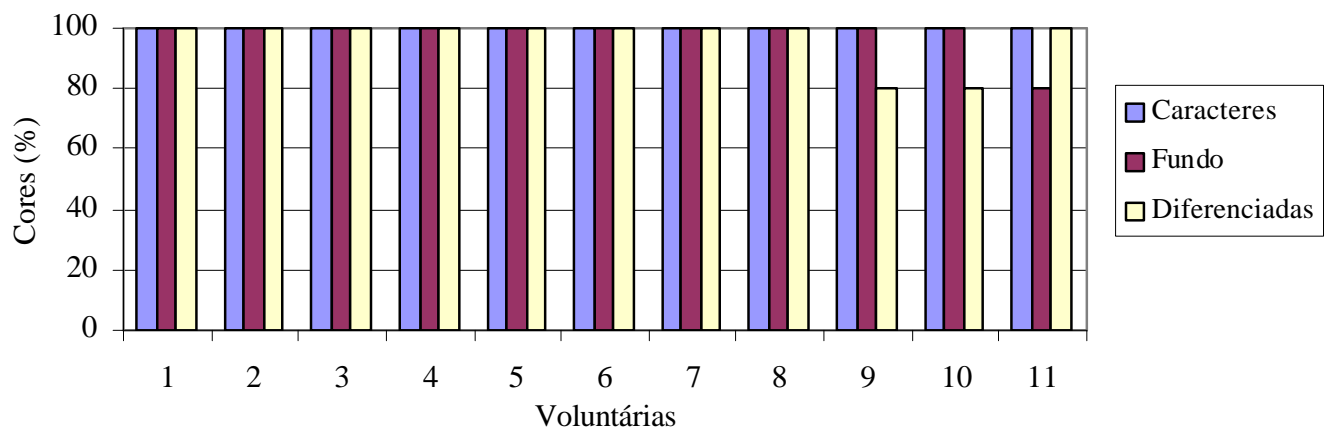

Figura 10 - Representação das cores dos caracteres, dos fundos das teclas e diferenciadas vs. voluntárias. 
O gráfico da Figura 11 indica o resultado das opiniões sobre a facilidade de local ização das vogais com letras ampliadas.

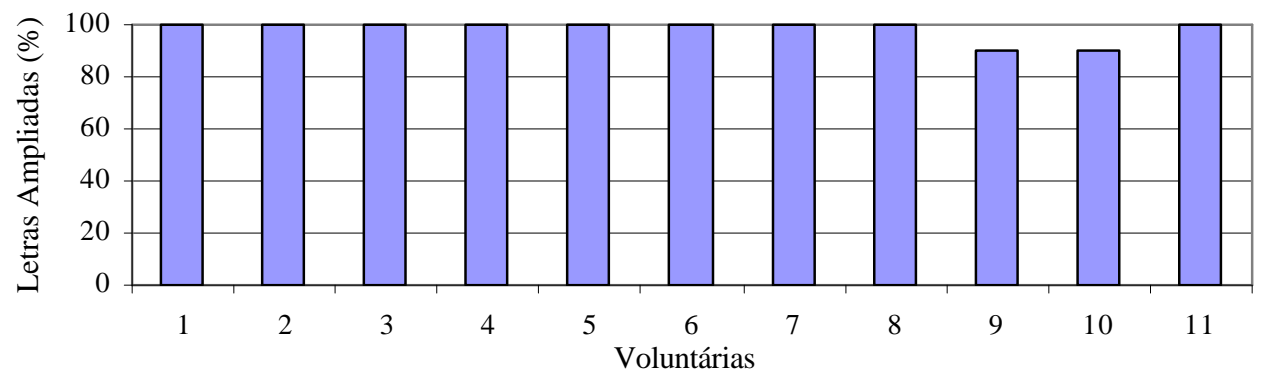

Figura 11 - Representação em porcentagem do uso de letras ampliadas vs. voluntárias.

Na Figura 12, ilustra-se graficamente o nível de facilitação de compreensão do layout de comunicação alternativa para portadores de paral isia cerebral com capacidade cognitiva preservada.

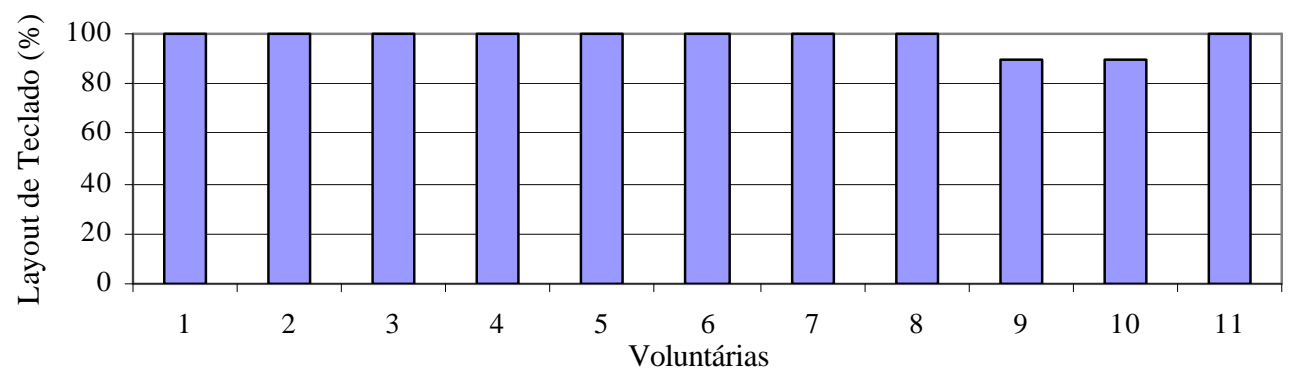

Figura 12 - Representação do nível de facilitação de compreensão do layout pelas voluntárias.

Para compor as teclas especiais de comunicação com ícones, 26 palavras ou frases do cotidiano de portadores de paralisia cerebral foram avaliadas, das quais 20 palavras ou frases ou idéias relacionadas foram sugeridas por todas as voluntárias e, portanto, escol hidas para compor o layout. Os resultados, em percentagem, com as sugestões estão representados na Tabela 1. 
Tabela 1 - Quantidade de Palavras e Frases escolhidas pelas voluntárias para compor as teclas especiais de comunicação.

\begin{tabular}{l|c}
\hline \multicolumn{1}{c|}{ Palavras ou Frases } & Quantidade Escolhida (\%) \\
\hline Brinquedo & 100 \\
Ela & 100 \\
Ele & 100 \\
Estou alegre & 100 \\
Estou com fome & 100 \\
Estou com sede & 100 \\
Estou triste & 100 \\
Família & 100 \\
Meu nome é & 100 \\
Não & 100 \\
Obrigado & 100 \\
Oi & 100 \\
Por favor & 100 \\
Preciso de ajuda & 100 \\
Professora & 100 \\
Qual seu nome? & 100 \\
Sim & 100 \\
Tchau & 100 \\
Vocês & 100 \\
Amigos & 9,09 \\
Escola & 9,09 \\
Não entendi & 9,09 \\
Onibus & 9,09 \\
Profissionais & 9,09 \\
Quer jogar comigo? & 9,09 \\
Vamos jogar novamente? & 9,09 \\
\hline
\end{tabular}

A nal isando-se os dados e as sugestões de ampliar os caracteres das teclas de funções e mudar o contorno das teclas de vogais para amarelo, obtevese como resultado o layout de teclado de comunicação alternativa para portadores de paralisia cerebral apresentado na Figura 13.

Observa-se no layout, medindo $35 \mathrm{~cm} \times 33 \mathrm{~cm}$, a presença de 3 grandes blocos. As teclas são basicamente de $2,5 \mathrm{~cm} \times 2,5 \mathrm{~cm}$, com caracteres pretos e fundo branco. O primei ro formado pelas teclas especiais de comunicação de $3,5 \mathrm{~cm}$ x 3,5cm contendo ícones de $2,1 \mathrm{~cm} \times 2,1 \mathrm{~cm}$, caracteres pretos com fonte A rial 14 e fundo branco.

$\mathrm{Na}$ primeira linha do segundo bloco estão representadas as teclas numéricas, com $2,5 \mathrm{~cm} \times 2,5 \mathrm{~cm}$, em seqüência crescente, seguidas dos sinais de soma, subtração, multiplicação e divisão. A segunda linha contém letras acentuadas e os caracteres @e \$. Todos os caracteres utilizam fonte A rial 32 com fundo branco. 


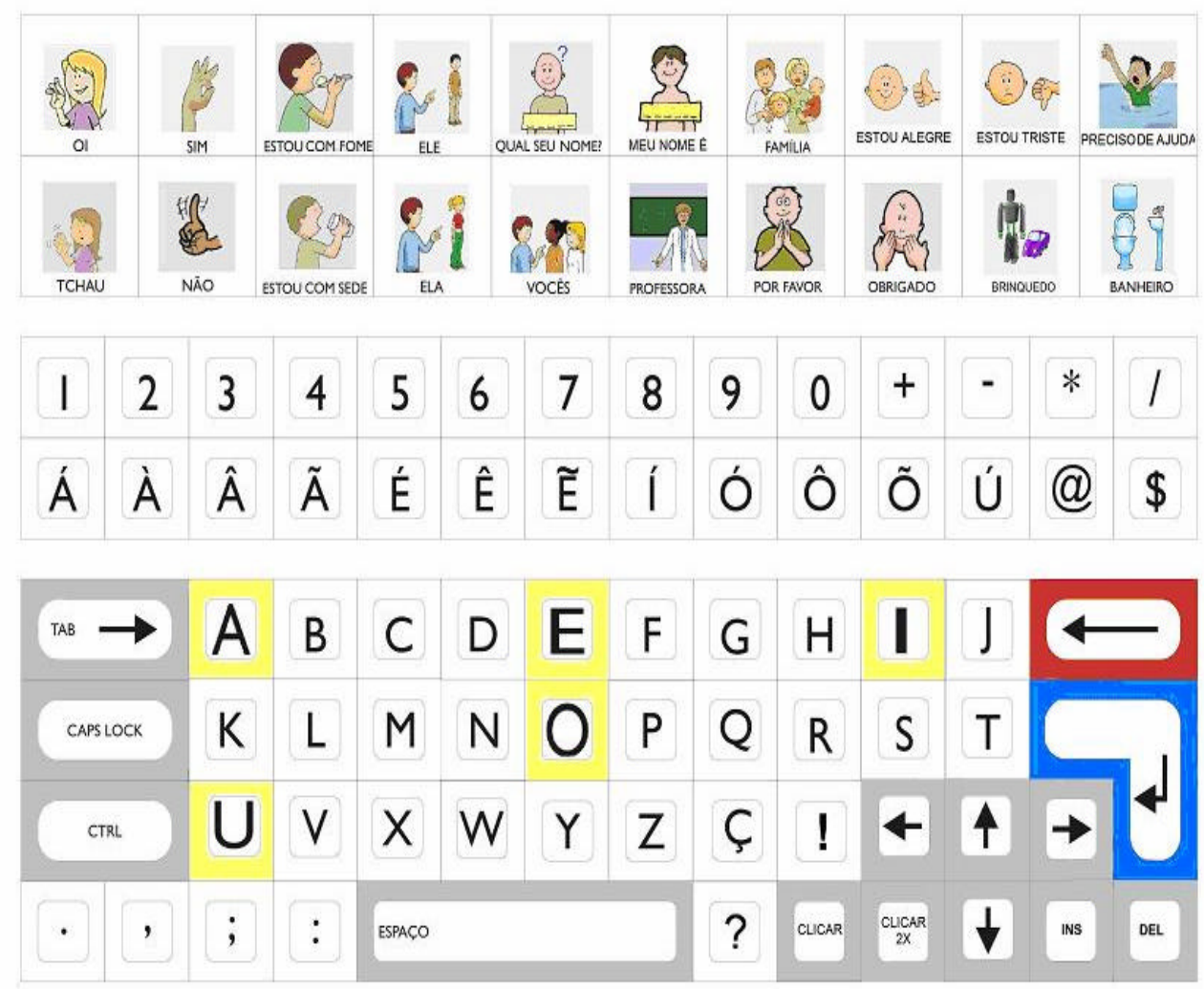

Figura 13 - Representação do layout de teclado de comunicação al ternativa para prancha de comunicação.

No último bloco, pode-se observar as teclas das letras em seqüência alfabética, todas medindo 2,5cm x 2,5cm. As consoantes utilizam fonte A rial 14 com fundo branco, evogais com fonte A rial 32 efundo amarelo. No lado esquerdo do teclado, encontram-se as teclas "TAB", "CAPSLOCK" e "CTRL", medindo $5 \mathrm{~cm} \times 2,5 \mathrm{~cm}$, com fonte Arial 14 e contorno de fundo da tecla na cor cinza. No lado direito, estão as teclas: "BACKSPACE", medindo $5 \mathrm{~cm} \times 2,5 \mathrm{~cm}$, na cor vermelha; "ENTER" na cor azul; teclas de orientação para cima, para baixo, para esquerda e para direita com setas na cor preta e fundo branco e as teclas "CLICAR", “CLICAR 2X", “INS" e "DEL" com fonte A rial 14 e contorno de fundo da tecla na cor cinza. Na parte central inferior do teclado, está a tecla de espaço medindo $10 \mathrm{~cm} \times 2,5 \mathrm{~cm}$. 


\section{DISCUSSÃo}

O layout do teclado de comunicação alternativa proposto representa uma inovação em projetos de teclado, por conter, num mesmo dispositivo, teclas especiais de comunicação e teclas características de um teclado convencional: teclas alfabéticas, numéricas e de funções. Outros dispositivos apresentam apenas as teclas de um teclado convencional, ou teclas especiais de comunicação, como, respectivamente, os comunicadores Lightw ritter (INTELLITOOLS, 2008) e G oT alk (CLIK, 2008). Essa inovação auxilia na redução do tempo de digitação e fadiga muscular dos usuários (JORDAN; HATTORI; NOHAMA, 2004).

Pode-se encontrar no mercado diferentes modelos de pranchas el etrônicas e sistemas informatizados de comunicação; projetados com símbolos, fotos, representações e recursos eletrônicos que podem permitir, inclusive, a vocalização da representação selecionada. Em sua maioria, esses dispositivos são versáteis, podendo possuir inúmeros layouts de representações que podem ser alterados deforma mecânica. Entretanto, esses disposi tivos são importados, como por exemplo, o M acaw 5 da Zygo Corp, Teclado Intell ikeys da Intellitools e Software Bosrdmaker da M ayer-Johnson LCC (CLIK, 2008). Portanto, esses dispositivos não são adaptados à realidade brasileira. O layout apresentado contempla teclas especiais de comunicação contendo ícones da Linguagem Brasileira de Comunicação Visual e a disposição de tais teclas pode ser reconfigurada por software.

Para compor o teclado, realizou-se um estudo de seqüências de letras e palavras utilizadas no cotidiano de portadores de paralisia cerebral com capacidade cognitiva preservada (COOK; HUSSEY, 2002; FERNANDES, 2005; MASSI, G., 2001; PELOSI, 2005).

A metodologia de design foi aplicada visando a adapatação do layout às necessidades físicas de seus usuários (LÖBACH, 2001). Para facilitar a localização das teclas no layout, aplicou-se a variação de tamanhos de teclas (WEBSTER et al., 1985). A escolha da cor preta para caracteres e símbolos e basicamente da cor branca para fundo e contorno de fundo baseia-se na literatura, que comprova que o uso de tais características facilitam a visual ização das teclas el etras, em especial por portadores de paral isia cerebral com capacidade cognitiva preservada (WEBSTER et al., 1985; CLIK, 2008).

As teclas especiais de comunicação são divididas em duas categorias: a primeira, composta por ícones com legenda e a segunda por teclas acentuadas. As teclas compostas por ícones com legenda facilitam a escolha de uma palavra ou frase com apenas uma indicação de informação, como, por exemplo: "Qual é o seu nome?". Caso o usuário tivesse que digitar a frase, o mesmo deveria digitar 
20 caracteres, mas com o uso de teclas especiais de comunicação, a mesma tarefa é realizada com a digitação de apenas 1 tecla. Portanto, essa facilidade auxilia na redução da fadiga muscular do usuário e na redução do tempo de digitação (MATIAS; NOHAMA, 2003).

\section{CONCLUSÕES}

O layout de teclado para comunicação alternativa dedicado à prancha de comunicação alternativa possui características de um teclado convencional aliadas às características de teclados de comunicação alternativa num mesmo dispositivo. Entretanto, prevendo as possíveis limitações e/ ou visuais de seus usuários, a ferramenta apresentada possui teclas, caracteres e símbolos ampliados em relação ao teclado convencional. As teclas especiais de comunicação possuem símbolos pictográficos da Linguagem Visual Brasileira de Comunicação, desenvolvida pela equipe de pesquisa do Dr. N ohama edistribuída gratuitamente com o software Prancha livre de Comunicação (www.ler.pucpr.br/ amplisoft). A lém dessas características, os tamanhos e cores das teclas, caracteres e símbolos foram escolhidos com o objetivo de facilitar a visualização e digitação de teclas por portadores de paralisia cerebral com capacidade cognitiva preservada.

O layout apresentou uma aceitação de 89,52\% por parte das voluntárias que fizeram parte da pesquisa. Portanto, será utilizado para compor um sistema informatizado de comunicação alternativa que se encontra em fase de testes. $\mathrm{O}$ acionamento do sistema informatizado ocorre de forma mecânica e pel o movimento da cabeça via sinal infravermelho. Essesistema contendo o layout será testado com os alunos da escola de educação especial onde a pesquisa do layout foi realizada.

Por fim, o layout de teclado descrito neste artigo e proposto como uma interface de comunicação alternativa voltada aos portadores de paralisia cerebral com capacidade cognitiva preservada e coordenação motora para acionar teclas (manualmente ou pel o movimento da cabeça), poderá auxiliar no processo de inclusão digital, social, educacional e inclusive profissional de seus usuários.

\section{ReferênCias}

BOONE, D. R.; PLANTE, E. Comunicação humana eseus distúrbios. 2. ed. Porto Alegre: Artes Médicas, 1994. p. 284-285.

BUZING, P. Comparing different keyboard layouts: aspects of qwerty, dvorak and al phabetical keyboards. D elft U niversity of Technology Articles, Delft, Mai. 2003. Disponível em: http:/ / 
www.st.ewi.tudelft.nl/ —buzing/ Articles/ keyboards.pdf. A cesso em: 12 maio 2008.

CHEN, Y. et al. Communication Aid System for Users with Physical Impairments. International Journal Computers \& M athematics with applications, v. 43, n. 6, p. 901-910, 1999.

CLIK. Acessibilidade ao Computador. Mai. 2008. Disponível em: http:www.clik.com.br. Acesso em: 12 maio 2008.

IIDA, I . Ergonomia: projeto e produção. 2. ed. São Paulo: E. Blücher, 2005.

JORDAN, M. et al. Mouse infravermel ho controlado pelos movimentos da cabeça - uma nova solução. In: CONGRESSO LATINO AMERICANO DE ENGEN HARIA BIOMÉDICA , 5, 2004, João Pessoa. A nais... João Pessoa, 2004. p. 493-496.

JORDAN, M.; HATTORI, D. M.; NOHAMA, P. Prancha pictográfica para comunicação alternativa com auxílio do computador. In: CONGRESSO LATINO AMERICANO DE EN GEN HARIA BIOMÉDICA, 5, 2004, João Pessoa. A nais... João Pessoa, 2004. p. 497-500.

KING, T. Assistive technology essential human factors. Allyn e Bacon, p 140-155, 1999.

LEDESM A , .; DEL TORO, A. Una nueva tecnología en comunicación aumentativa. TerapiaO cupacional.com. Espanha, 2004. Disponível em: http:/ / www.terapia-ocupacional .com. Acesso em: 12 maio 2008.

LIEGEL, L.A.; N OHAMA , P. Proposta delayout deteclado para comunicação alternativa. In: CONGRESSO IBEROA MERICANO SOBRE TECN OLOGIASDE APOIO A PORTADORES DE DEFICIÊNCIA , 4, 2006, Vitória. A nais...Vitória: Copigraf Gráfica eEditora Ltda, 2006, p. CO207-CO209.

LÖBACH, B. D esign industrial: bases para a configuração dos produtos industriais. 1. ed. São Paulo: Edgard Blücher, 2001.

MASSI, G. Linguagem eparal isia cer ebral: um estudo decaso do desenvolvimento da narrativa. Editora Maio, 2001. p. 7-22.

MATIAS, D.; NOHAMA, P. Teclado virtual com predição de palavras. In: SEMINÁRIO ATIID - ACESSIBI LIDA DE, TI E IN CLUSÃO DIGITAL, 2, 2003, São Paulo. A nais ... São Paulo, 2003, 4p.

OSOWSKY, J. et al. Controle do cursor do mouse pelo movimento da cabeça usand o câmera CCD e processamento de imagem. In: CONGRESSO LATINO AMERICANO DE EN GEN HARIA BIOM ÉDICA , 3, 2004a, João Pessoa. A nais... João Pessoa, 2004a, p.441-444.

OSOWSKY, J. et al. Mouse controlado pelo rastreamento do movimento dos ol hos In: CONGRESSO LATINO AMERICANO DE ENGENHARIA BIOMÉDICA, 3, 2004b, João Pessoa. A nais... João Pessoa, 2004b, p. 473-476.

PELOSI, M. Comunicação alternativa. Tecnologia Assistiva eComunicação Alternativa, Rio de Janeiro, 2005. Disponível em: http:/ / www.comunicacaoalternativa.com.br. A cesso em: 12 maio 2008.

RICHAUDEAU, F.; MENDIBELZÚA, J. Los secretos dela comunicación eficaz. Bilbao : Mensajero, 1976.

SHIRMER, C. R.; BROWNING, N.; BERSCH, R. Atendimento educacional especializado deficiência física. Brasília: SEESP / SEED / MEC, 2007. 
LIEGEL, L. Ap.; GOGOLA, M. M. R.; NOHAMA, P.

SICORDE. Estudos censitários. Brasília, 2000. Disponível em: http: www.mj.gov.br/ sedh/ ct/ corde/ dpdh/ sicorde/ estudos_cens1.asp\#conteudo. A cesso em: 12 maio 2008.

VALENTE,J. A. A capacidade da criança com paralisia cerebral resolver o teste deseriação. N ied, Campinas, 1987. Dispovível em http:/ / www.nied.unicamp.br/ publicaçoes/ memos/ MEM 006.pdf. Acesso em: 12 maio 2008.

WEBSTER, J. G. et al . E letronic devices for rehabilitation. N ew York: John Wiley \& Sons, 1985.

Recebido em 28/ 05/ 2008

Reformulado em 03/ 10/ 2008

A provado em 04/ 12/ 2008 